\title{
The Cytotoxic Effect of Rtks Inhibitors on Glioblastoma Cells A Mathematical Model for Treatment Protocols Optimization
}

\author{
CORINA BRANDUSA ${ }^{1}$, BOGDAN-IONEL VATU ${ }^{1}$, STEFANA OANA PURCARU ${ }^{1}$, \\ STEFAN-ALEXANDRU ARTENE ${ }^{1}$, SANDRA ALICE BUTEICA ${ }^{2}$, DANIELA ELISE TACHE ${ }^{1}$, \\ CRISTIAN ADRIAN SILOSI ${ }^{3}$, CITTO IULIAN TAISESCU ${ }^{1}$, OANA ALEXANDRU ${ }^{4}$, \\ OLIVIAN PUIU STOVICEK ${ }^{5}$, ALIN DEMETRIAN ${ }^{6}$, ANICA DRICU ${ }^{1 *}$ \\ ${ }^{l}$ University of Medicine and Pharmacy of Craiova, Department of Functional Science, 2-4 Petru Rares Str., 200349, \\ Craiova, Romania \\ ${ }^{2}$ University of Medicine and Pharmacy of Craiova, Department of Drug Control, 2-4 Petru Rares Str., 200349, Craiova, \\ Romania \\ ${ }^{3}$ University of Medicine and Pharmacy of Craiova, Department of Surgery, 2 Petru Rares Str., 200349, Craiova, \\ Romania \\ ${ }^{4}$ University of Medicine and Pharmacy of Craiova, Department of Neurology, 2 Petru Rares Str., 200349, Craiova, \\ Romania \\ ${ }^{5}$ Titu Maiorescu University Department of Pharmacology, 189 Gheorghe Sincai Blvd., 040317, Bucharest, Romania \\ ${ }^{6}$ University of Medicine and Pharmacy,Department of Thoracic Surgery, 2 Petru Rares Str., 200349, Craiova, Romania
}

\begin{abstract}
Medical oncology has seen an exponential growth in the last 20 years with the vast majority of malignancies receiving new therapeutic options with substantial benefits to patients' survival and quality of life. Glioblastomas (GBMs), however, have remained largely incurable, with over $90 \%$ of patients dying within 5 years of diagnosis. The estimation of a dose-effect type ratio, regarding the action of an oncological drug on tumor cells, leads to relevant conclusions in establishing the optimal medication, specific to the chemotherapeutic act. The identification of the optimal dose of agent is very important, based on experiments on cell lines with regards to cellular kinetics. In this study, we developed a mathematical model based on the specific transfer function of a dose-response action type of a drug on tumor cells in vitro.
\end{abstract}

Keywords: mathematical model, glioblastoma, simulation

GBM is the most aggressive type of brain tumour and although advances have been made in recent years, the prognosis for patients suffering from this cancer remains abysmal [1]. This is due, in part, to a very poor knowledge of the dynamics of growth and proliferation which confer the distinctively aggressive nature of this particular tumor. GBM is more common in adults, with a median overall survival of approximately 14.6 months and a progression-free survival of 6.9 months. Additionally, the 5-year survival rate is under 10\%, making GBMs one of the most aggressive and hard to treat tumors in oncological practice $[2,3]$. Even with the constant improvement of the surgical techniques employed in current practice, recurrences happen in almost $99 \%$ of the cases mainly because of the malignant cells capacity to detach and invade adjacent structures. The incidence of GBM is 3 to 5 cases per 100000 people in Europe and United States of America [4,5]. Additionally, it was observed that the incidence of GBM increases with age (7584 years old) and it is more common in white males [6].

The standard of care treatment has a relative poor prognostic due to the GBM's high recurrence. Although many new treatment options have emerged, the best approach for the initial treatment is based on maximal surgical resection followed by concomitant temozolomide (TMZ) and radiotherapy with adjuvant TMZ chemotherapy shortly afterwards [1]. New molecular-based approaches have been under investigation for primary and recurrent GBMs with bevacizumab (Avastin $\left.{ }^{\circledR}\right)$ a VEGF (vascular endothelial growth factor) inhibitor, erlotinib (Tarceva $\left.{ }^{\circledR}\right)$ or gefitinib (Iressa ${ }^{\circledR)}$ both EGFR (epidermal growth factor receptor) inhibitors providing promising results in preclinical settings [7]. However, all of these agents presented mediocre results in clinical trials, remaining viable options only as salvage therapy after recurrence or progression, which usually happens in $99 \%$ of recorded cases [5, 8-10].

Many studies have presented the importance of mathematical models that help in the prognosis and behavior of untreated and treated GBMs.

Researchers from several groups have studied the in vivo mathematical models for the growth and proliferation rate of gliomas. A mathematical model was developed for glioma growth and invasion of the brain tissue, using the equation for the "rate of change for the cell population density" [11]. In addition, mathematical models are important

*email: anica.dricu@live.co.uk, anica.dricu@umfcv.ro

All authors contributed equally to this work. 
for understanding the biological mechanisms responsible for the differences in proliferative kinetic of patients with same type of cancer $[11,12]$. Swanson et al developed a mathematical model that can help to estimate the efficacy of tumour treatments, in patients diagnosed with GBM $[13,14]$.

The description in an abstract form of a behavioral system of the tumour cells through mathematical models is the base of numerical simulation, with important implications for the knowledge of cells complex developments. In this study, we aim to build a mathematical model, focused on the interactions between the tumour cells' proliferation rate, aggression and saturation rates.

We used one cell line derived from a primary tumour (GBM). Based on the evolution of this cell line we made a model analysis of the biological system variables.

\section{Material and methods \\ Reagents}

Cell culture media, Tyrphostine AG1433, SU1498 and Imatinib® were purchased from Sigma-Aldrich (St. Louis, MO, USA). The drugs were diluted in dimethyl sulfoxide (DMSO) to a stock concentration of $10 \mathrm{mM}$ and stored at $20{ }^{\circ} \mathrm{C}$. The DMSO concentration was below $0.1 \%$ when the inhibitors were added in the cultured medium. Fetal Bovine Serum (FBS), Penicillin/Streptomycin antibiotics, Trypsin, Phosphate-buffered saline (PBS) were obtained from Gibco by Life Technologies ${ }^{\mathrm{TM}}$.

\section{Cell culture and treatment}

Low passage cell culture used in this study was established from tissue obtained from a patient diagnosed with GBM at the "Bagdasar-Arseni" Emergency Hospital, Bucharest, Romania. The cell line was established according to standard procedures [15]. For experimental purposes, cells were seeded in 6 wells plates in DMEM and treated with different concentrations of small molecule inhibitors tyrosine kinases, SU1498, AG1433 and STI-571 (1 $\mu \mathrm{M}, 2 \mu \mathrm{M}, 5$ $\mu \mathrm{M}, 10 \mu \mathrm{M}, 20 \mu \mathrm{M}, 40 \mu \mathrm{M}, 80 \mu \mathrm{M}$ ), for 3 days. Appropriate control groups with culture medium and 0.01\% DMSO were included. Each of the three experiments was performed in triplicate.

\section{IC50 calculation}

In order to determine the inhibitory concentration for the used drugs that kills 50\% of GB10B cells (IC50 values) the applied formula was: IC50 $=[(50-\mathrm{M}) /(\mathrm{N}-\mathrm{M})] \times(\mathrm{P}-\mathrm{Q})+\mathrm{Q}$, with $\mathrm{M}$ being the first percent inhibition that is less than $50 \%, \mathrm{~N}$ representing the first percent inhibition that is higher or equal to $50 \%$, Q and $\mathrm{P}$ being the concentrations of inhibitors that corresponds to $\mathrm{X} \%$ and respectively $\mathrm{Y} \%$ inhibition.

\section{Cell proliferation and survival}

For assay proliferation, cells were seeded into 6-well plates at a concentration of $2 \times 10^{5}$ cells/well. Cells were incubated in standard MEM medium overnight and then treated with various concentrations of SU1498, AG1433 and STI-571 and incubated for 3 days.

After the incubation time, the cells were trypsinized and a uniform cell suspension was counted in a Bürker hemocytometer, using trypan blue. Each experiment was performed in triplicate and repeated three times.

\section{Mathematical models}

The mathematical models are based on the first order transfer function, FT1:

$$
f_{n}^{*}=L^{-1}[(100-10) \cdot W /(W s+1)]+10,
$$

where: $\mathrm{K} 1$ corresponds to the value of $\mathrm{D} / \mathrm{IC} 50=0 ; \mathrm{K}_{1}=100 \%$, $\mathrm{K} 2$ represents the system-imposed minimal value for cellular proliferation $(\mathrm{K} 2=10 \%)$.

The 1/E constant results from mathematical simulation after validation of the simulation model, based on the correlation between the data series.

Cellular viability was determined using the fn function (unaffected cellular fraction) calculated as a percentage of cells alive in comparison to the control group, which represent $100 \%$ by default. The mathematical simulation was designed using the Matlab tool with the Simulink extension. 
The statistical analysis was expressed as mean \pm standard deviation $( \pm \mathrm{SD})$ and statistical comparison was expressed using Student t-test. Statistically significant was considered for a p-value $<0.05$. All experiments were performed in triplicate.

Pearson's R correlation coefficient was used to estimate the correlation in linear regression. A Pearson $\mathrm{R}$ value between 0.5 and 1 was considered to be a positive correlation between the experimental values and the simulation.

\section{Results and discussion}

Very little is known about the intrinsic mechanisms which make up for the highly invasive nature of GBMs. One of the greatest setbacks in developing a viable approach for treating GBMs is the lack of therapeutic agents which can be used in a clinical setting. This is due to a couple of factors. The first and the most important is the presence of the blood brain barrier (BBB) which blocks the passage for over $90 \%$ of the agents used in the current clinical setting [16, 17]. Secondly, GBMs have a propensity to quickly develop resistance to the therapeutic agents which penetrate the BBB, through multiple molecular pathways [18-20].

In our experiment we established a mathematical model based on the IC50 observed in an experimental setting for each therapeutic agent used on the GB10B GBM cell line. We compared the simulated results obtained using the mathematical model with the observed experimental value. A Pearson R value between 0.5 and 1 was considered to be a positive correlation between the experimental values and the simulation (fig. 1).

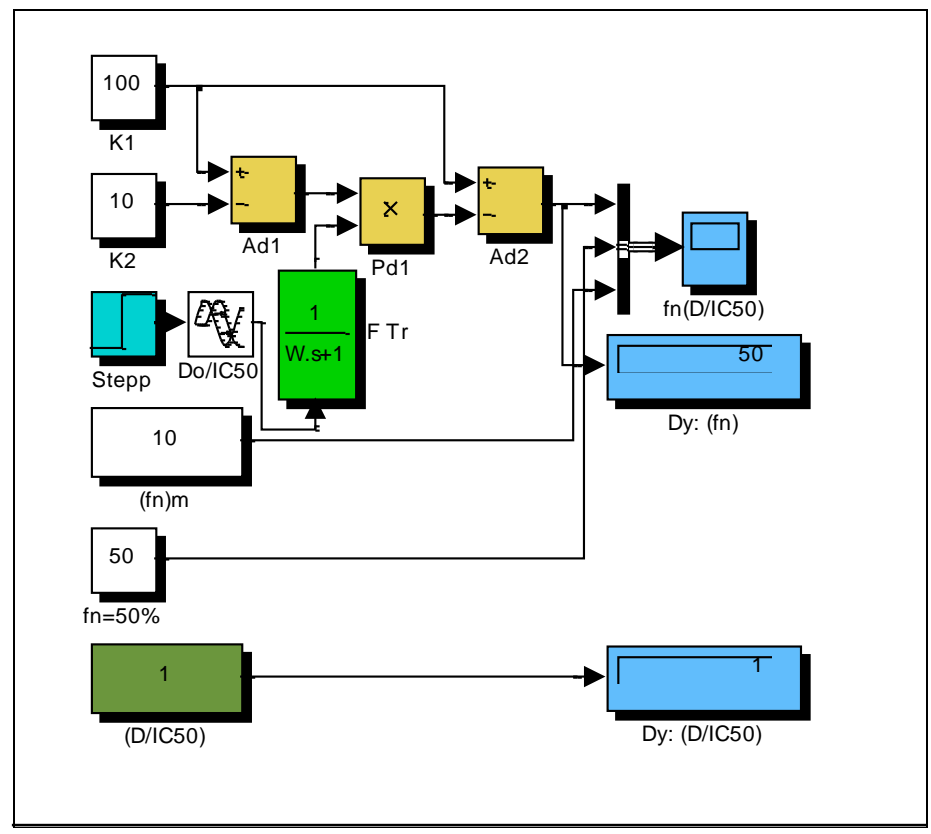

Fig. 1. Model of a mathematical simulation involving a dose-response type action of an inhibitor in a GBM cell line. The model is based on a first order transfer function, FT1.

Entry data is set by the $\mathrm{K} 1, \mathrm{~K} 2, \mathrm{fn}(\mathrm{m})$, $\mathrm{fn}=50 \%$ and D/IC50. Calculation blocks are based on the Ad1, Pd1, Ad2 and the specialized blocks FTr, Do/IC50, Stepp. Exit blocks are based on the numerical blocks Dy:fn, Dy:(D/IC50) and the generating block $\mathrm{fn}(\mathrm{D} / \mathrm{IC} 50)$

Imatinib is a molecular targeted therapy used in the treatment of Philadelphia chromosome-positive leukemia. Receiving approval in 2001, it is one of the first targeted therapies used in the treatment of any kind of malignancy. Several clinical trials have, so far, presented no significant clinical results for patients with recurrent malignant gliomas being treated with Imatinib [21, 22]. This poor response can be attributed, in part, to the very low perfusion rate of Imatinib through the BBB, with Imatinib levels being 92-times lower in the cerebrospinal fluid in comparison to the blood of patients receiving the drug [23].

In our experiment, Imatinib presented a cytotoxicity in the GB10B cell line of $5.5 \%$ for the minimal dose of $1 \mu \mathrm{M}$, $16 \%$ for $2 \mu \mathrm{M}, 28 \%$ for $5 \mu \mathrm{M}, 40 \%$ for $10 \mu \mathrm{M}, 45 \%$ for and $20 \mu \mathrm{M}$ and over $50 \%$ for the $40 \mu \mathrm{M}$ and the $80 \mu \mathrm{M}$ (Figure 2A). The mathematical model predicted no cytotoxicity for the 1, 2, and $5 \mu \mathrm{M}$ doses resulting in high residual values: -5.52 for $1 \mu \mathrm{M},-16.64$ for $2 \mu \mathrm{M}$ and -28.34 for $5 \mu \mathrm{M}$. The highest difference in cytotoxicity was observed for the $10 \mu \mathrm{M}$ dose $(60.2 \%$ observed vs. $98.36 \%$ predicted), resulting in a residual value of -38.15 . For the highest doses in our experiment, $40 \mu \mathrm{M}$ and $80 \mu \mathrm{M}$, the cytotoxicity induced by Imatinib was in correlation with the values observed in the mathematical simulation: (46.2\% vs $45.3 \%$ ) and (42.2\% vs $40.2 \%$ ) (fig. $2 \mathrm{~B})$. Overall, the Pearson R value was 0.83 indicating a positive correlation between the experimental and simulated values (fig. 2B). 


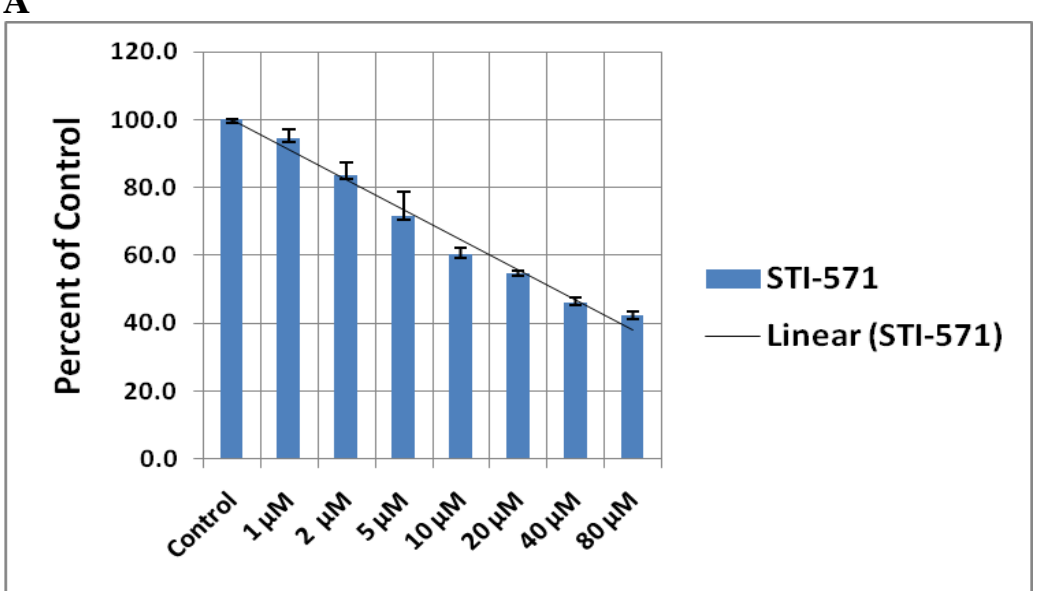

B

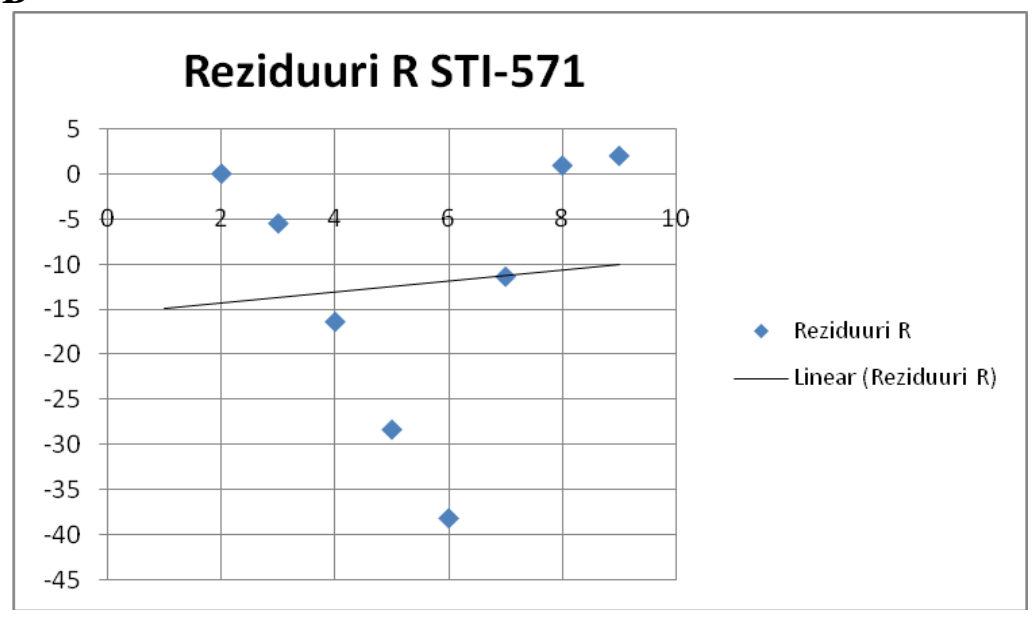

Fig. 2. (A) fn(D) on the GB10B cell line after Imatinib treatment using 1 $\mu \mathrm{M}, 2 \mu \mathrm{M}, 5 \mu \mathrm{M}, 10 \mu \mathrm{M}, 20 \mu \mathrm{M}, 40$ $\mu \mathrm{M}$ and $80 \mu \mathrm{M}$ doses. Results are presented as percentage of control and are calculated as an average \pm SD of three independent experiments.

(B) Distribution of the R residual values (errors), in the GB10B cell line after Imatinib treatment

SU1498 is an anti-VEGFR 2 inhibitor, which has been previously used for inhibiting angiogenesis in different types of cancer in preclinical models, such as GBMs [24, 25]. Observed cytotoxicity was $6 \%$ for the $1 \mu \mathrm{M}$ dose, $13 \%$ for $2 \mu \mathrm{M}$ SU1498, $29 \%$ for $5 \mu \mathrm{M}, 36 \%$ for $10 \mu \mathrm{M}, 48 \%$ for the $20 \mu \mathrm{M}$ dose, $56 \%$ for the $40 \mu \mathrm{M}$ dose and $62 \%$ for the $80 \mu \mathrm{M}$ dose (fig. 3A). Given that the mathematical model predicted no citotoxicity for the 1,2 and $5 \mu \mathrm{M}$ doses and very low citotoxicity for $10 \mu \mathrm{M}(12 \%)$, we observed high residual values: -5.37 for $1 \mu \mathrm{M},-13.36$ for $2 \mu \mathrm{M},-28.64$ for $5 \mu \mathrm{M}$ and -24.16 for $10 \mu \mathrm{M}$ (fig. 3B). The mathematical model prediced very similar results to those observed in the experiment for the final 3 doses in our experiment resulting in low residual values: -6.29 for $20 \mu \mathrm{M}, 4.48$ for $40 \mu \mathrm{M}$ and 2.36 for $80 \mu \mathrm{M}$ (fig. 3B). Overall, the Pearson R value observed for the SU1498 experiment was 0.90 indicating a very strong correlation between the observed experimental values and the mathematical simulation (fig. 3B).

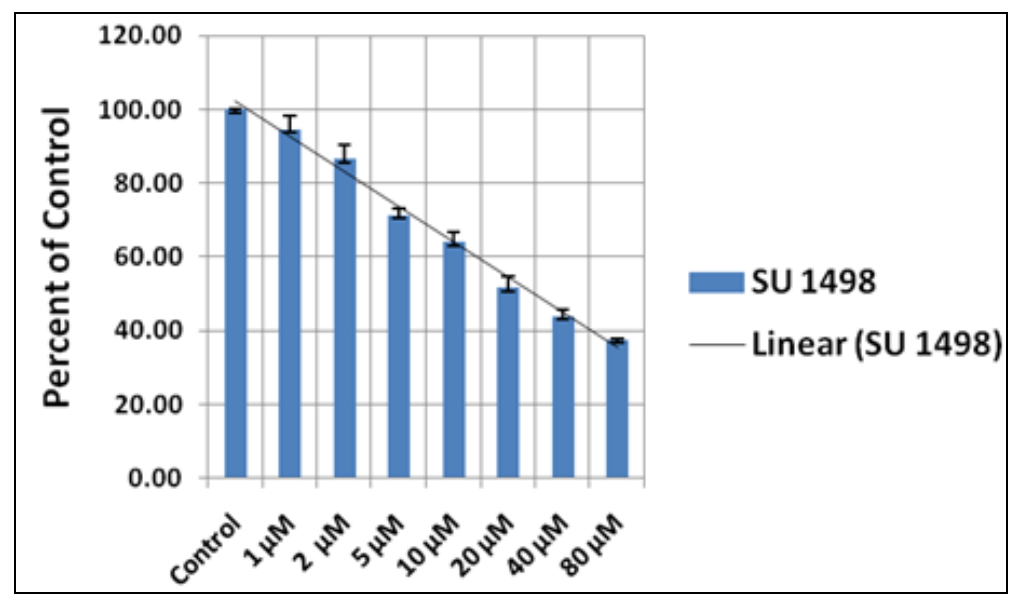

Fig. 3. (A) fn(D) on the GB10B cell line after SU 1498 treatment using $1 \mu \mathrm{M}, 2 \mu \mathrm{M}, 5 \mu \mathrm{M}, 10 \mu \mathrm{M}$, $20 \mu \mathrm{M}, 40 \mu \mathrm{M}$ and $80 \mu \mathrm{M}$ doses.

Results are presented as percentage of control and are calculated as an average \pm SD of three independent experiments. 


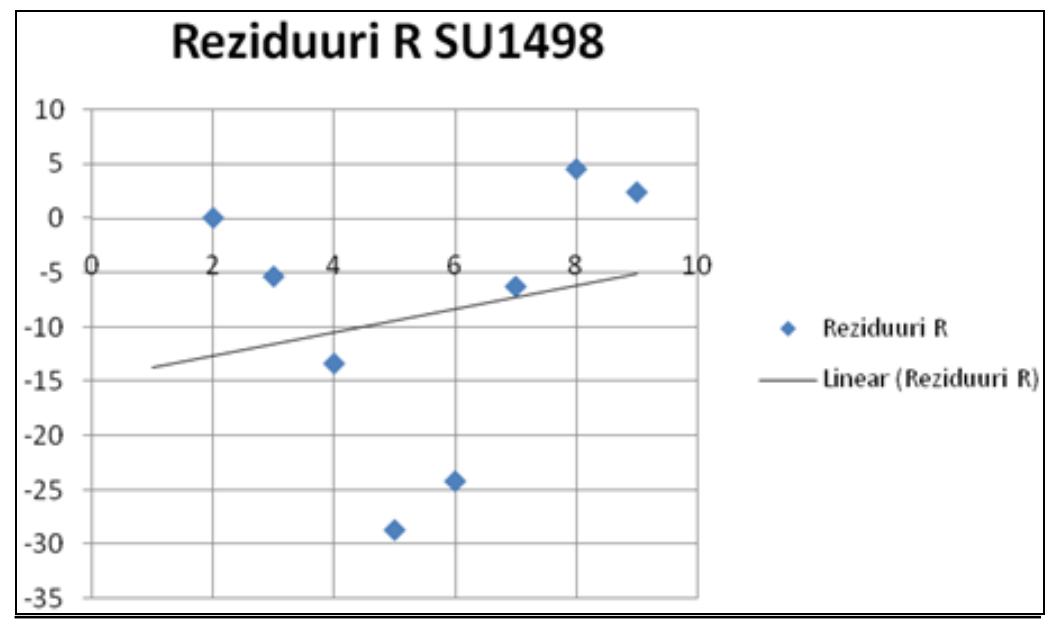

Fig. 3. (B) Distribution of the $\mathrm{R}$ residual values (errors), in the GB10B cell line after SU 1498 treatment

Similarly to SU1498, AG1433 is a PDGFR inhibitor which has been succesfully used in preclinical GBM models $[24,25]$. The recorded cytotoxicity in our experiment was $5 \%$ for the $1 \mu \mathrm{M}$ dose, $10 \%$ for the $2 \mu \mathrm{M}$ dose, $21 \%$ for 5 $\mu \mathrm{M}, 31 \%$ for $10 \mu \mathrm{M}, 38 \%$ for $20 \mu \mathrm{M}, 48 \%$ for $40 \mu \mathrm{M}$ and $54 \%$ for $80 \mu \mathrm{M}$ dose (fig. $4 \mathrm{~A}$ ). The mathematical simulation predicted no cytoxicity for the $1,2,5$ and $10 \mu \mathrm{M}$ doses and very low citotoxicity for the $20 \mu \mathrm{M}$ dose (12\%), resulting in high residual $\mathrm{R}$ values between the simulated and observed values: -5.09 for the $1 \mu \mathrm{M}$ dose, -12.20 for $2 \mu \mathrm{M},-23.32$ for $5 \mu \mathrm{M},-30.55$ for $10 \mu \mathrm{M}$ and -26.75 for the $20 \mu \mathrm{M}$ (fig. 4B). However, the simulation predicted highly similar values for the $40 \mu \mathrm{M}$ and $80 \mu \mathrm{M}$ doses in comparison to the experimental results: $51.6 \%$ vs. $56.83 \%$ for $40 \mu \mathrm{M}(-5.22$ residual value) and $46.3 \%$ vs. $45.91 \%$ (0.39 residual value) for the $80 \mu \mathrm{M}$ AG1433 dose, respectively (fig. 4B). Overall, the Pearson R value calculated was 0.83 indicating a very strong correlation between the values predicted by the mathematical simulation and the values observed in the experiment (fig. 4B).

A

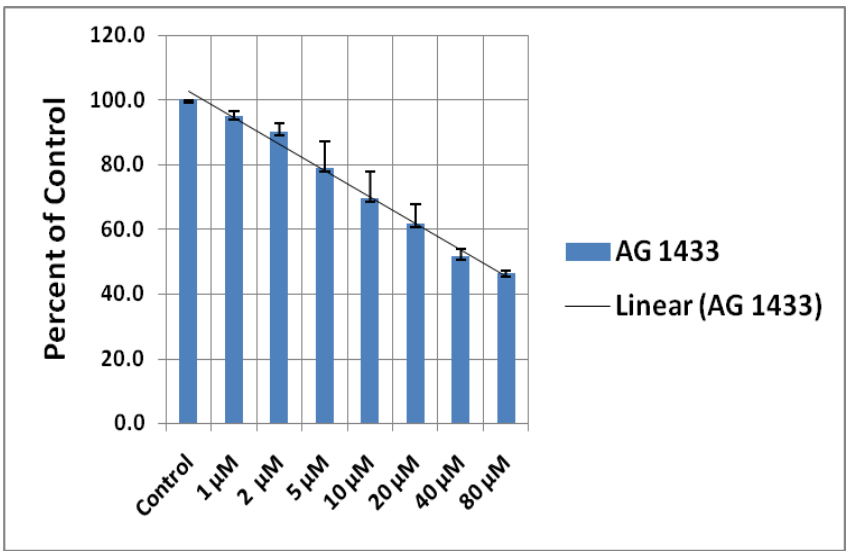

B

\section{Reziduuri R AG1433}

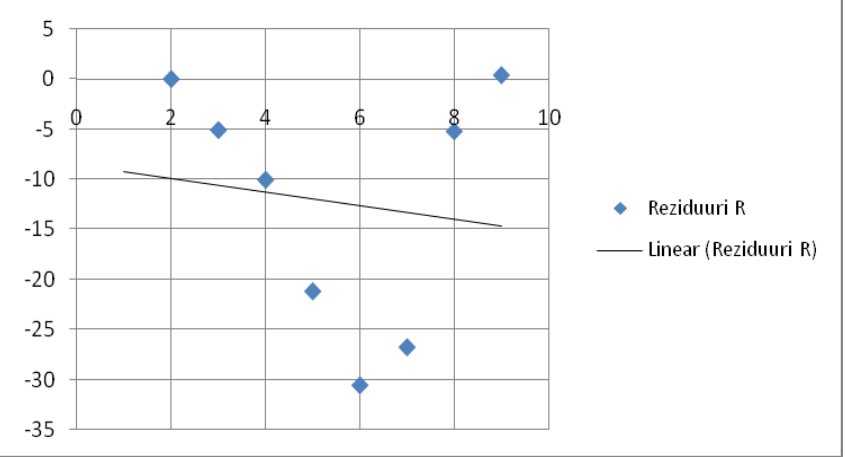

Fig. 4. (A) fn(D) on the GB10B cell line after AG 1433 treatment using $1 \mu \mathrm{M}, 2$ $\mu \mathrm{M}, 5 \mu \mathrm{M}, 10 \mu \mathrm{M}, 20 \mu \mathrm{M}, 40 \mu \mathrm{M}$ and 80 $\mu \mathrm{M}$ doses. Results are presented as percentage of control and are calculated as an average $\pm \mathrm{SD}$ of three independent experiments
Fig. 4 (B) Distribution of the $\mathrm{R}$ residual values (errors), in the GB10B cell line after AG 1433 treatment 


\section{Conclusions}

We have conducted a study that demonstrates that treatment with Imatinib, SU 1498 and AG 1433 inhibitors induces cell death in the GB10B GBM cell line, in vitro. A mathematical model was proposed using Matlab for describing the dose-response activity of the Imatinib, SU 1498 and AG1433 inhibitors, based on the results observed in the experimental setting. After comparing the experimental and predicted results using the mathematical model, the Pearson R coefficient was positive, with values between 0.5 and 1 for all the three inhibitors used in our experiment. This indicated a very strong correlation between the two sets of values, thus validating the value of the mathematical model in predicting the dose-dependent behavior of inhibitors used in preclinical settings.

Acknowledgements: This paper received financial support through the Grant PN-II-ID-PCE-2011-3-1041, UEFISCDI, Romania.

\section{References}

1. STUPP, R., ET AL., Effects of radiotherapy with concomitant and adjuvant temozolomide versus radiotherapy alone on survival in glioblastoma in a randomised phase III study: 5-year analysis of the EORTC-NCIC trial, Lancet Oncol., 10(5), 2009, p. 459-4.066.

2. DAS, S. AND P.A. MARSDEN, Angiogenesis in glioblastoma, N. Engl. J. Med., 369(16), 2013, p. 1561-1563.

3. LEE, P.Y., ET AL., The Aurora kinases inhibitor VE-465 is a novel treatment for glioblastoma multiforme, Oncology, 84(6), 2013, p. 326335 .

4. DUNN, G.P., ET AL., Emerging insights into the molecular and cellular basis of glioblastoma, Genes. Dev., 26(8), 2012, p. $756-784$.

5. WELLER, M., ET AL., Standards of care for treatment of recurrent glioblastoma--are we there yet?, Neuro. Oncol., 15(1), 2013 , p. 4-27.

6. OLAR, A. AND K.D. ALDAPE, Using the molecular classification of glioblastoma to inform personalized treatment, J. Pathol., 232(2), 2014, p. 165-177.

7. HALATSCH, M.E., ET AL., Epidermal growth factor receptor pathway gene expressions and biological response of glioblastoma multiforme cell lines to erlotinib, Anticancer Res., 28(6A), 2008, p. 3725-3728.

8. CHAKRAVARTI, A., ET AL., RTOG 0211: a phase 1/2 study of radiation therapy with concurrent gefitinib for newly diagnosed glioblastoma patients, Int. J. Radiat. Oncol. Biol. Phys., 85(5), 2013, p. 1206-1211.

9. KARPEL-MASSLER, G., ET AL., Erlotinib in glioblastoma: lost in translation?, Anticancer Agents Med. Chem., 11(8), 2011, p. $748-755$.

10. YANG, S.B., ET AL., Bevacizumab combined with chemotherapy for glioblastoma: a meta-analysis of randomized controlled trials, Oncotarget, 8(34), 2017, p. 57337-57344.

11. SWANSON, K.R., E.C. ALVORD, JR., AND J.D. MURRAY, Virtual brain tumours (gliomas) enhance the reality of medical imaging and highlight inadequacies of current therapy, Br. J. Cancer, 86(1), 2002, p. 14-18.

12. NEAL, M.L., ET AL., Discriminating survival outcomes in patients with glioblastoma using a simulation-based, patient-specific response metric, PLoS One, 8(1), 2013, p. e51951.

13. CARAPANCEA, M., ET AL., Growth factor receptors signaling in glioblastoma cells: therapeutic implications, J. Neurooncol., 92(2), 2009, p. 137-147.

14. SWANSON, K.R., R.C. ROSTOMILY, AND E.C. ALVORD, JR., A mathematical modelling tool for predicting survival of individual patients following resection of glioblastoma: a proof of principle, Br. J. Cancer, 98(1), 2008, p. 113-119.

15. DANCIULESCU, O.T., R. FOLCUTI, AND A. DRICU, Temozolomide and targeted therapy against epidermal growth factor receptor in glioma, Int. J. Clin. Exp. Med., 9(8), 2016, p. 15249-15261.

16. PHAN, D.T., ET AL., Blood-brain barrier-on-a-chip: Microphysiological systems that capture the complexity of the blood-central nervous system interface, Exp. Biol. Med. (Maywood), 242(17), 2017, p. 1669-1678.

17. YANG, Z.Z., ET AL., Delivering siRNA and Chemotherapeutic Molecules Across BBB and BTB for Intracranial Glioblastoma Therapy, Mol. Pharm., 14(4), 2017, p. 1012-1022.

18. ALEXANDRU, O., ET AL., The Influence of EGFR Inactivation on the Radiation Response in High Grade Glioma, Int. J. Mol. Sci., 19(229), 2018, 18p.

19. AZUAJE, F., K. TIEMANN, AND S.P. NICLOU, Therapeutic control and resistance of the EGFR-driven signaling network in glioblastoma, Cell Commun. Signal, 13, 2015, p. 23.

20. PERAZZOLI, G., ET AL., Temozolomide Resistance in Glioblastoma Cell Lines: Implication of MGMT, MMR, P-Glycoprotein and CD133 Expression, PLoS One, 10(10), 2015, p. e0140131.

21. RAYMOND, E., ET AL., Phase II study of imatinib in patients with recurrent gliomas of various histologies: a European Organisation for Research and Treatment of Cancer Brain Tumor Group Study, J. Clin. Oncol., 26(28), 2008, p. 4659-4665.

22. RAZIS, E., ET AL., Phase II study of neoadjuvant imatinib in glioblastoma: evaluation of clinical and molecular effects of the treatment, Clin. Cancer Res., 15(19), 2009, p. 6258-6266.

23. TAKAYAMA, N., ET AL., Imatinib mesylate has limited activity against the central nervous system involvement of Philadelphia chromosome-positive acute lymphoblastic leukaemia due to poor penetration into cerebrospinal fluid, Br. J. Haematol., 119(1), 2002, p. 106108.

24. POPESCU, A.M., ET AL., Targeting the VEGF and PDGF signaling pathway in glioblastoma treatment, Int. J. Clin. Exp. Pathol., 8(7), 2015, p. 7825-7837.

25. PURCARU, S.O., ET AL., Effect of VEGFR, PDGFR and PI3K/mTOR Targeting in Glioblastoma, Curr.Health Sci. J., 41(4), 2015, p. 325332.

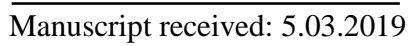

